https://doi.org/10.48009/1_iis_2010_184-191

\title{
WHAT'S THIS TWITTER ALL ABOUT? AN E-PATIENT'S END-USER COMMUNITY (EUCY)
}

\author{
Elaine Winston, Hofstra University, acserw@ hofstra.edu
}

\begin{abstract}
Currently, there is a strong push by the government to develop a robust e-patient environment. Health care organizations may increase their effectiveness in meeting the needs of a growing e-patient population through the implementation of high quality social networking applications. These applications help to support and maintain a valuable and informed enduser community (EUCY). An in-depth literature review identifies three characteristics that have an impact on information exchange inherent to social networks: number of members, contact frequency, and type of knowledge. Data from a case study of a juvenile diabetic using Twitter helps to demonstrate these characteristics. Managerial implications of this study are discussed that can help IT and health administrators when implementing social networks.
\end{abstract}

Keywords: Social Networking, Twitter, End-user community (EUCY), e-Patients, Health Information Management, Case study

\section{INTRODUCTION}

Currently, there is strong push by the government to develop a robust e-patient environment. A main problem in reaching this goal is the lack of trust in the health care providers [16, 31] and ambiguity about information quality [20]. As a result, health care organizations find it difficult to develop a collaborative relationship with e-patients [6]. This may lead to lower quality health care as both patient and provider become dysfunctional in isolated silos.

Health care organizations may increase their effectiveness in meeting the needs of a growing epatient population through the implementation of social networking applications. According to the Hospital Social Media List, 660 hospitals in the United States reported using social network applications, which includes Twitter [2]. Twitter has been publicized as a way to gather and exchange important real-time health data [24]. The number of Twitter users is projected at 75 million [23].
The paper is organized as follows: First, a literature review focuses on Twitter as a place to share high quality health information. Social learning and coordination theories help to identify network characteristics and types of knowledge that form valuable end-user communities for health care. Next, an analysis of case study data identifies how Twitter is used by a chronically ill patient. Managerial implications of this study are discussed that can help IT and health care administrators when implementing social networks.

\section{LITERATURE REVIEW}

A social network application for health care becomes valuable when it meets the expectations of members as a platform for the exchange of ideas and quality information [26]. Twitter's free online service and 140 byte limit for each tweet (i.e., message) simplifies communication. The use of Twitter for health care relies on a privacy feature and authentication through member description, contact information and visual image.

\section{End-user community (EUCY)}

The end user of a Twitter application is a group of individuals. The group forms a community that expresses itself by employing a common language and similar practices [32]. This end-user community (EUCY) follows the rules of an unspoken agreement to help ensure it remains well informed and successful. A member that does not follow the policies of the community will be blocked from effectively using the application.

The success of Twitter applications in forging epatient relationships requires health care professionals to pay attention to distinct end-user communities (EUCYs) that develop over time. Characteristics that help to identify a EUCY include: number of members, contact frequency and type of knowledge. 


\section{Size}

Most Twitter users have a small number of actual friends that they tweet with compared to the number of followers and followees that they declare [12]. This implies the existence of at least two distinct networks: 1) a sparse network of friends (i.e. anyone who a member has directed a post to at least twice) and 2) a dense one made up of followers and followees [12]. Research suggests that the sparser network is more important in driving Twitter use [12, 17]. Evaluating health information communicated through tweets remains a key responsibility of the small core group of knowledgeable entities (i.e., epatients, friends, doctors, and health care system personnel) who share similar interests and overlapping goals.

Some users join with the objective of having as many followers as possible [25]. An established community, with reliable and dense interconnectivity, not only keeps existing members happy, but also entices contacts of current members to participate. A EUCY will grow with new members who manage related health issues. E-patients interact with other members who they feel they know and trust. This connection builds a strong sense of belonging to a dynamic community and increases the potential success of the Twitter application.

\section{Contact Frequency}

There is an increasing amount of available health information at Web sites and government agency portals. In addition consumers provide expertise in the form of blogs and microblogs. Studies report that patients attain more than $50 \%$ of their information at Web sites rather than from local doctors [30] and go online for first and second medical opinions [10, 19]. The increased delivery of information across social networks requires increased coordination [14]. Coordination, although associated with improved efficiency of resources, leads to increased costs (e.g., alignment and governance overhead) [34].

Using Twitter, consumers and providers of health information enter into real time personal conversations. These conversations develop naturally because of a common thread, such as e-patients seeking knowledge for a specific medical concern. This reduces coordination costs associated with sharing information and collectively taking action. Twitter provides the tools and motivation for health care organizations to deliver more of the same types of health information over the Internet as was done physically.

The amount of information that can be shared among a EUCY increases and results in less information being inadvertently left out. This suggests that both health information and services become less vulnerable to inconsistencies in procedure and quality [34]. Patient provider agreements are able to become formalized more completely. In this case, a health care organization will look to organize and contract more health services.

\section{Loose coupling}

In Twitter there is no one entity in charge of the EUCY. This enables members to participate in many diverse conversations. At any given time members who pool their knowledge and insights may need access to another reputable and knowledgeable member or group [34]. This results in the potential number of separate interactions to become excessively complex to manage. Providing long term formal commitments among members becomes infeasible. Therefore, small and loosely coordinated social network communities thrive [34].

\section{Tight coupling}

Conversely, the effective functioning of a group with regulations and/or time constraints for communication requires tightly connected members through the use of a centralized decision making unit [18]. The central entity channels interactions [33]. This reduces the number of links maintained in the network and improves operability. Twitter enables this entity to succeed through three mechanisms: 1 . identification of a coordinator, 2. hash tags (i.e., \#nursemeet) and 3. add-on services to filter tweets based on hashtags or key words. For example, to organize a "Twittinar" (i.e., a seminar on Twitter) to happen at a specific time and day there is an entity that governs the event and requires the use of a hash tag to identify participation. This centralized formation enables EUCY growth to coincide with the development of long-term relationships.

\section{Types of Knowledge}

Health care consumers and providers transfer and reuse explicit knowledge. This study refers to two types of explicit knowledge: experiential and clinical knowledge.

\section{Experiential knowledge}


Experiential knowledge is gained through active involvement in a medical event as opposed to a priori (i.e., before experience) knowledge [34]. Since people like to work with other people, Twitter encourages members to share their health care stories. If the right people tell their health stories, then other members will pay attention and pass around this information. Often, through the process of sharing information and experiences EUCY members learn from one other as well as have an opportunity to develop themselves professionally as topic authorities [13].

EUCYs prefer informal forms of communication, which is often represented by ordinary chatter [15]. The sharing of intimate aspects of ones daily life promotes knowledge transfer through virtual interpersonal contacts rather than through formally written documents. The dependency of Twitter applications for casual interpersonal contact hinders codification and systematic access of information more than the reliance on a technology platform [9]. EUCYs drive decision making by e-patients, as well as by health care providers, to rely more on analogical and correlative thinking, rather than on rational and analytic thinking $[7,11]$.

\section{Clinical knowledge}

Clinical knowledge reflects the information or facts about a particular health care subject. Health care providers accumulate this type of knowledge throughout their professional training and through guidelines. Clinical guidelines represent a set of plans assisting practitioners and technicians in their decisions concerning appropriate health care delivery. Technical knowledge includes: what was done (facts), how it is and was done (procedural and contextual), and what could be done better (analytic). Evidence based methodology relies on collectively reinforced, internalized, tacit guidelines and experiences shared among practitioners within their specific domains [8].

Hospitals use Twitter to share clinical information, such as the real time broadcasts of surgeries that present new approaches to knee replacement and robot-assisted operations [5, 21]. Some suggest that the integration of Twitter and electronic medical records (EMR) will become a highly effective method for tracking and distributing data that ranges from clinical test results to pandemic notification [3, 29]. Studies have found that accurate information is distributed through Twitter. (i.e., the swine flu outbreak, and recommended clinical procedures and medications) [1].
E-patients use Twitter for clinical data collection to update health records anytime and almost anywhere. Monitoring medical activities though the use of traditional diary based recordings often results in inaccurate recall of clinical results reported at an earlier time $[4,27,28]$. Twitter negates the difficulty associated with information recall and not having the appropriate equipment to record medical events.

Based on the above literature review the following questions guided this research:

- How can a chronically ill patient use Twitter for health information?

- How can health care organizations and epatients collaborate through a EUCY?

\section{METHODOLOGY}

A case study was selected because a primary goal is to understand how a chronically ill patient uses Twitter to acquire health information from a community. Identifying characteristics of the community provides insight on building social value. Yin (1994) recommends case study as the preferred research strategy when "the focus is on a contemporary phenomenon within some real-life context," when "how" questions are being posed (p. 1 ), and when the context involves events over which the investigator has little or no control.

This case study uses a positivist view in that it relies on past literature and empirical data and the insights of the researcher to build or extend theory [22].

\section{Data Collection Strategy}

A data collection strategy employed in this study was an open-ended interview. In order to protect participant confidentiality, a pseudonym was generated for the patient. With this caveat the patient declared a willingness to discuss his experiences openly.

A second data collection method used was an evaluation of online scripts from Ken's Twitter community. The Twitter account used for this study, which started December 2009 and remains active, contained over 200 posts that were written by members of Ken's network. The use of multiple data 
collection methods provides stronger substantiation of constructs.

\section{Case Description}

The participant, Ken See, is a juvenile diabetic. Ken is 53 years old and has been taking an average of 3 insulin shots a day for 29 years. Ken decided to use Twitter to become better informed about his medical condition and new insulin pump technology. His Twitter community represents a population that tag themselves with descriptions related to "diabetic" (e.g. diabetes, juvenile diabetes or other variation of the words).

The long term time frame of Ken's illness provides a contextual scenario that is important to any study on the use of a social network systems for health information for a number of reasons: 1) provides a perspective on the effectiveness of social networks as a knowledge platform for a highly educated and informed participant and 2) explores a demographic group that did not grow up with computers and social networks, yet who will require these technologies to help manage their personal health information.

\section{FINDINGS}

The findings discuss key topics: (1) Social network characteristics: size, contact frequency and types of knowledge (2) emergence of the end user as a community, and (3) contributors to quality.

\section{Group size and contact frequency}

Ken began using the Twitter application by following 4 members. During the first six months the community grew to 46 members ( 26 followers and 22 following). Ken does not want to become part of a larger group. He plans to manage the tweets related to his health condition.

As more members followed me and tweeted it became more difficult to remain focused on a consistent theme: juvenile diabetes.

A separate group of friends developed when Ken began to use a facility of Twitter that allowed for direct messages. This small group provided a platform for knowledge exchange related solely to juvenile diabetes.

One person that I tweeted, actually direct messaged, was my age and a lifetime juvenile diabetic. In my day to day life I never get a chance to talk with someone like that - most of the time the information that I gather is from health care professionals.

Ken valued the conversational activities with members that are outside of his physical social community.

It gives you a forum for a conversation. In my case the topic concerned my chronic illness that is juvenile diabetes. I was able to interact with people in different types of conversations all in one place and anytime. Normally this would not be available to me in my world of people who I communicate with.

\section{Types of Knowledge}

Predominantly, experiential knowledge was tweeted. For example, tweets reported on daily events in one's life, practical guides on taking a blood sugar count, and problems in maintaining sports activities.

Clinical knowledge exchange was not common. In fact, a tweet at a Podiatrist for advice on foot care, which is a critical concern due to poor circulation associated with juvenile diabetes, resulted in a tweet to see your own doctor. One member in the community continuously tweets on news regarding stem cell research. When Ken requested information concerning research on the Islets of Langerhans only one follower responded with a tweet to a link. Islets transplant is an area of personal interest for Ken. He commented that once he went to read the information posted that he found it too scientific.

Ken pinpointed information that was most useful and noted how he endorsed this information.

It was tweeted that the insulin pump is easy to become comfortable with from someone in a similar situation. Further, in Ken's comparison to more scientific knowledge on the subject of Insulin pumps, he revealed that a peer's experience had more value than a clinical opinion.

Medical professionals provide clinical descriptions of using an Insulin Pump. I know it's the better way to go. The exchange with my doctor is colder. I'm sure his intention is good. The doctor would say you should do it. It improves control of blood sugars. 
Joy of Living also said, "Way to go because of control over sugar." His tweet felt more personalized. I could relate to him.

Some of the information tweeted deprecated the implied contract of Twitter, which is to develop a sustainable knowledge platform. An irresponsible tweet from a member of Ken's community suggested that he go to a particular Web site to get information and help for his condition. Ken followed the link to the site. The site www.diabetestype12.info/ offered no reliable information. Its only apparent purpose is as a platform for Google advertisements.

Interestingly, Ken's EUCY provides more value to him than the previous support groups he had participated in to become more educated about his chronic illness. In speaking about a juvenile diabetes support group he commented,

It seemed like everyone who attended the group meetings at Winthrop University Hospital was paranoid. They went to the meetings to vent. The paranoia - it was crazy I was a diabetic for a short time. There was one woman who went to all the meetings and discussed her procedure for giving herself a shot. When she took a shot she put down a towel. It was washed and wrapped every day in a plastic bag to keep it and everything she used sterile.

Ken revealed how differently he perceived his illness.

I give shots on the expressway going 60 miles an hour through my jeans while changing gears. Now, I am not saying that is the right way to do it. I stopped going to meetings. At the time, I felt as though I had a totally different mindset than most diabetics.

Ken filtered out tweets by blocking members from his EUCY that he did not want to have contact with. This individual control combined with implicit community rules enhanced his experience using Twitter as a support and knowledge management application.

I blocked the podiatrist from my account. When time is of the essence in a busy work week - I can decide that I don't want to read his tweets. This is in contrast to attending a meeting. I didn't have to feel as though I was acting rude by walking out on the podiatrist or on the other hand listening to him talk for 45 minutes with his goal to get me to come to his office.

Ken discussed Twitter's most dissatisfying aspect:

You have to have a constant filtering process of both tweets and members. You can block them if it's something you are not interested in. However, this task requires attention and takes away time from doing something more worthwhile.

It is the interactions among members that build an application with an objective. End user computing in terms of social network technology reflects a community. This finding, along with support from the literature, suggests how a EUCY emerges and influences the value of the application, as shown in Table 1.

\section{Summary of findings}

A key finding of this study is the rapid development of competence and openness in a EUCY. This finding was a surprise. Generally the qualities of group competence and openness take time to build. On the other hand, the time a EUCY spends on filtering both followees and information becomes a disadvantage to using Twitter. Limited resources determine the members' use of Twitter. Worthless tweets are a violation of the EUCY implied policy. Each tweet is a new claim on community time. Therefore, it must offer some value higher than something else the member and group already does. Social learning and coordination theories help to identify and describe key constructs that form a social networking community.

\section{CONCLUSION}

The use of Twitter for communicating health information about juvenile diabetes is extremely valuable. This effort was explored from both the epatient activities and the participation of the EUCY. A limitation of this case study is the reliance on one e-patient. The research offers a starting point for future studies on the use of Twitter as a knowledge base and platform for information exchange. The literature review identified numerous benefits to using Twitter in health care. A key advantage is the ability for health care organizations to connect with 
an e-patient population in a friendly EUCY

environment.

Table 1. Emergence of a EUCY

\begin{tabular}{|c|c|c|c|}
\hline \multicolumn{3}{|c|}{ TWEETS } & \multirow[b]{2}{*}{ Action: EUCY } \\
\hline Type & Evidence & Responses: Content & \\
\hline $\begin{array}{l}\text { Informal } \\
\text { Query }\end{array}$ & $\begin{array}{l}\text { Has anyone tried } \\
\text { Tropo } 50 \text { reduced } \\
\text { sugar orange juice? } \\
\text { (juvdiab*) }\end{array}$ & 1: “Tropo 50 huh?” & $\begin{array}{l}\text { Maintain quality control over } \\
\text { knowledge. } \\
\text { Identify an ad-hoc adviser(s). }\end{array}$ \\
\hline $\begin{array}{l}\text { Formal } \\
\text { Request }\end{array}$ & $\begin{array}{l}\text { Anyone have } \\
\text { information about } \\
\text { Islets of Langerhans? } \\
\text { (juvdiab) }\end{array}$ & $\begin{array}{l}\text { 1: Link to book on Islet } \\
\text { transplants as a solution to } \\
\text { juvenile diabetes. }\end{array}$ & $\begin{array}{l}\text { Provide information to community } \\
\text { concerns and expectations. } \\
\text { Guide to locating clinical } \\
\text { knowledge. }\end{array}$ \\
\hline $\begin{array}{l}\text { Slice of } \\
\text { Life } \\
\text { Story }\end{array}$ & $\begin{array}{l}\text { In the hospital now } \\
\text { (sixuntilme*) }\end{array}$ & $\begin{array}{l}\text { Many: 'Well-wishers' to } \\
\text { sixuntilme concerning her } \\
\text { experience with juvenile } \\
\text { diabetes and now pregnancy. } \\
\text { sixuntilme is a highly ranked } \\
\text { and long time tweeter. }\end{array}$ & $\begin{array}{l}\text { Create an 'inter-personal' diary. } \\
\text { Spur of the moment thoughts and } \\
\text { creative ideas. }\end{array}$ \\
\hline $\begin{array}{l}\text { Personal } \\
\text { Concern }\end{array}$ & $\begin{array}{l}\text { What can you tell me } \\
\text { about the insulin } \\
\text { pump? (juvdiab) }\end{array}$ & $\begin{array}{l}\text { Few: Personal experiences } \\
\text { that advocate using an insulin } \\
\text { pump; links to additional } \\
\text { information. }\end{array}$ & $\begin{array}{l}\text { Participate to share experiential } \\
\text { knowledge. }\end{array}$ \\
\hline
\end{tabular}

* sixuntilme and juvdiab are Twitter accounts.

\section{REFERENCES}

1. AJIC, (2010). American Journal of Infection Control, 38 (3)

2. Bennett, E. (2010). Hospital social network list. http://ebennett.org/hsnl/.

3. Brownstein, J., Freifeld, C., Chan, E., Keller, M., Sonricker A., Mekaru, S. and Buckeridge, D., (2009). Information technology and global surveillance of cases of 2009 H1N1 Influenza. The New England Journal of Medicine, 362(18), 1731-1735.

4. Deiss, D., Bolinder, J., Riveline, J. P., Battelino, T., Bosi, E., Tubiana-Rufi, N., Kerr, D., \& Phillip, M. (2006). Improved glycemic control in poorly controlled patients with type 1 diabetes using real-time continuous glucose monitoring. Diabetes Care, 29 (12), 2730-2732.
5. Dolan, P., (2009). Should doctors use Twitter? American Medical Association. [online],http://www.ama-ssn.org/amednews/ 2009/06/29/bisa0629.htm

6. Ferguson, T. (2007). e-Patients: How they can help us heal healthcare. Eds Meredith Dreiss Susannah Fox Gilles Frydman Joe and Terry Graedon.

7. Fung, Y., (2010). On the very idea of correlative thinking. Philosophy Compass, 5(4), 296-306.

8. Gabbay, J., \& le May, A., (2004). Evidence based guidelines or collectively constructed mind lines: Ethnographic study of knowledge management in primary care. British Medical Journal, 329, 1-5.

9. Ghosh, B. and Scott, J., (2005). Comparing knowledge management in health care and technical support organizations. IEEE 
Transactions on Information Technology in Biomedicine, 9(2), 162 - 168.

10. Gualtieri, L., (2009). The doctor as the second opinion and the Internet as the first. Proceedings of the 27th International Conference on Human factors in Computing Systems, Boston, MA, USA.

11. Hall, D. and Ames, R., (1998). Chinese philosophy. Craig (Ed.), Routledge Encyclopedia of Philosophy, London: Routledge. Retrieved May 10, 2010, from http://www.rep.routledge.com/article/G001S ECT2

12. Huberman, B., Romero, D. and Wu, F., (2009). Social networks that matter: Twitter under the microscope. First Monday, 14, http://firstmonday.org/htbin/cgiwrap/bin/ojs/ index.php/fm/article/viewArticle/2317/2063

13. Lave, J. \& Wenger, E., (1991). Situated Learning: Legitimate Peripheral Participation, New York, NY: Cambridge University Press.

14. Malone, T. (1990). What is coordination theory and how can it help design cooperative work systems? Proceedings of the 1990 ACM Conference on Computersupported Cooperative Work, 357 - 370.

15. Mischaud, E., (2007). Twitter: Expressions of the whole self. Electronic MSc Dissertation Series, London School of Economics and Political Science.

16. Norris, P. (2007). Skeptical patients: performance, social capital and culture. The Trust Crisis in Healthcare; Causes, Consequences and Cures. Ed. David A. Shore. New York, NY: Oxford University Press

17. Owyang, J. (2008). Understanding HP lab's Twitter research. http://www.webstrategist.com/blog/2008/12/08/understandin g-hp-labs-twitter-research/

18. Parameswaran, M., Susarla, A. and Whinston, A., (2001). P2P networking: An information-sharing alternative, Computer, 34(7), 31-38.

19. Purcell K., Rainie, L., Mitchel A., Rosenstiel, T. and Olmstead, K., (2010). Understanding the participatory news consumer. [online]. http://www.pewinternet.org /Reports/2010/Online-News.aspx
20. Risk, A and Dzenowagis J. (2001). Review of internet health information quality initiatives, Journal of Medical Internet Research, 3(4), e28.

21. Rogers, C., (2009). Henry Ford posts live surgery blog. The Detroit News [online], http://detnews.com/article/20090210/BIZ04/ 902100383/Henry-Ford-posts-live-surgeryblog\#ixzz0nHWbi54H

22. Rubin, H., and Rubin, I., (1995). Qualitative interviewing: the art of hearing data, Thousand Oaks, CA: Sage Publications Inc.

23. rjmetrics, (2010). New data on Twitter's users and engagement, http://themetricsystem.rjmetrics.com/2010/0 1/26/new-data-on-twitters-users-andengagement/

24. Scanfeld, D., Scanfeld, V. and Larson, E. L. (2010). Dissemination of health information through social networks: Twitter and antibiotics. American Journal of Infection Control, 38 (3), 182-188.

25. Siegler, M. (2009). [online], http://techcrunch.com/2009/04/20/howmany-new-twitter-users-post-oprah-a-lotmaybe-over-a-million/

26. Shirky, C. (2008). Here comes everybody: The power of organizing without organizations, New York, NY: The Penguin Press

27. Shay, L., (2008). Self-monitoring and weight management. [online], Journal of Nursing Informatics, 12(1) [online]. http://ojni.org/12_1/shay.html

28. Stone, A., Shiffman, S., Schwartz, J., Broderick, J., and Hufford, M., (2003). Patient compliance with paper and electronic diaries. Controlled Clinical Trials, 24 (2), 182-199.

29. Thorman, C., (2009). Twitter: Growing Virally But Can It Stop Viruses? http://www.softwareadvice.com/articles/med ical/twitter-growing-virally-but-can-it-stopviruses-106300/\#ixzz0nI9ZA1Eb

30. Undem, T., (2010). Consumers and Health Information Technology: A National Survey, Oakland, CA: California Health Care Foundation

31. Whetten, K, Leserman, J. Whetten, R., Ostermann, J , Thielman, N. Swartz, M. and Stangl, D. (2006). Exploring lack of trust in care providers and the government as a 
barrier to health service use. American

Journal of Public Health, 96(4), 716-721.

32. Wenger, E. (2000). Communities of practice: the structure of knowledge sharing. Knowledge Horizons: The Present and the promise of knowledge management, (eds) Despres, C. and Chauvel, D. London: Butterworth-Heinemann Publishing.

33. Winston, E., (2006). An exploratory study of end user computing strategy: managing for compliance and innovation. Issues in Information Systems, 7(2), 110 - 114.

34. Winston - Spiegel, E., (1996). Classifying and assessing the information technology strategy process. Proceedings of the First INFORMS Conference on Information Systems and Technology, Washington, DC. USA.

35. Yin, R. K. (1994). Case study research: Design and methods, 2d ed. Thousand Oaks,.CA: Sage Publications Inc. 